\title{
Double-Wire Technique for Access Into a Protruding Aorto-Ostial Stent for Treatment of In-Stent Restenosis
}

\author{
Stanley J. Chetcuti, MD, and Mauro Moscucci, ${ }^{*}$ MD \\ We report a case of restenosis following ostial stenting of the right coronary artery with \\ protrusion of the stent into the aorta. Treatment was only possible after a guidewire \\ advanced through a lower strut was used to lever the guide, and a second guidewire was \\ advanced through the true lumen. Catheter Cardiovasc Interv 2004;62:214-217. \\ ๑ 2004 Wiley-Liss, Inc.
}

Key words: stents; aorto-ostial stenosis; restenosis

\section{INTRODUCTION}

Elastic recoil is a common finding after angioplasty of aorto-ostial coronary artery or vein graft stenoses [1-4] and stenting is now commonly employed in an attempt to reduce this phenomenon $[5,6]$. Stenting in this location, however, is technically challenging, and it is associated with several risks, including retrograde dissection into the aorta, stent recoil, and stent loss or imprecise positioning. We report a patient with restenosis of an aortoostial stent and protrusion of the stent into the aorta, preventing intubation of the ostium with the guide catheter, and the technique that was used to overcome this difficulty.

\section{CASE REPORT}

A 76-year-old female presented to the cardiac catheterization laboratory following a non-ST segment elevation myocardial infarction. She had known coronary artery disease, having undergone PTCA of her proximal LAD 5 years earlier. Cardiac catheterization revealed a $60 \%$ ostial RCA stenosis and a $90 \%$ distal RCA stenosis with thrombus. The ostium of the RCA was easily engaged with an 8 Fr JR4 guiding catheter with side holes. Rheolytic thrombectomy was performed in the distal RCA. A $3.0 \mathrm{~mm} \times 18 \mathrm{~mm}$ ACS Duet stent was then deployed in the distal RCA and a $3.5 \mathrm{~mm} \times 13 \mathrm{~mm}$ ACS Duet stent (Guidant, Santa Clara, CA) was deployed at the ostium. The ostial stent was expanded and then flared with the delivery balloon inflated to a maximum of 16 atm. Seven months later, she presented with recurrent angina. Coronary angiography showed the left main coronary artery to be without any significant angiographic disease. The left anterior descending coronary artery had a proximal $50 \%$ stenosis and a distal $50 \%$ stenosis. The left circumflex had an ostial $60 \%$ stenosis. Attempts to intubate selectively the ostium of the right coronary with a diagnostic JR4 catheter were unsuccessful. Therefore, nonselective angiography was performed. The ostial stent was slightly extending into the aortic sinus. This stent had $60 \%$ in-stent restenosis. The distal stent had $70 \%$ in-stent restenosis. Attempts to engage the right coronary artery for percutaneous intervention, using multiple 6 Fr guiding catheters including a JR4, Hockey Stick 1, an Amplatz right 1 and 2, and an Amplatz left 1 were unsuccessful. The 6 Fr Hockey Stick guiding catheter, however, permitted the best proximity to the stent ostium. Through this guiding catheter, a Balance Heavy Weight (BHW; Guidant) guidewire was passed into the stent via a lower stent strut and was then used as support to lift the guiding catheter and make it more coaxial with the stent ostium. A Balance Middle Weight wire (BMW; Guidant) was then successfully advanced through the stent central lumen into the distal vessel (Figs. 1-4, 7). The distal and proximal restenotic lesions were then dilated using a 3.5 and a $4.0 \mathrm{~mm}$ Coyote balloons, respectively (Boston Scientific). Before the first balloon dilatation, the uninflated balloon was advanced and retracted multiple times through the stent to confirm lack of entrapment. After the last balloon inflation, there was a $<$ $30 \%$ residual stenosis in the proximal lesion and a $0 \%$

Division of Cardiology, Department of Internal Medicine, University of Michigan Health System, Ann Arbor, Michigan

*Correspondence to: Dr. Mauro Moscucci, Division of Cardiology, University of Michigan Health System, University Hospital, TC B1226, 1500 E Medical Center Drive, Ann Arbor, MI 48103.

E-mail: moscucci@umich.edu

Received 26 June 2003; Revision accepted 11 February 2004

DOI 10.1002/ccd.20062

Published online in Wiley InterScience (www.interscience.wiley.com). 


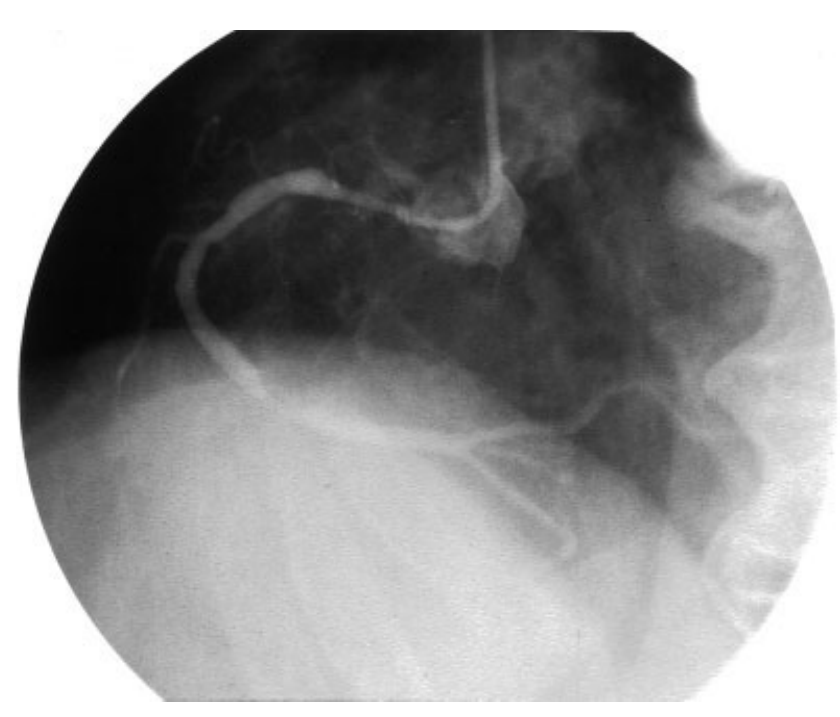

Fig. 1. Right coronary artery (RCA) in left anterior oblique (LAO) view. The guiding catheter is positioned slightly below the origin of the RCA. There is a $70 \%$ distal in-stent restenosis and a $60 \%$ ostial in-stent restenosis.

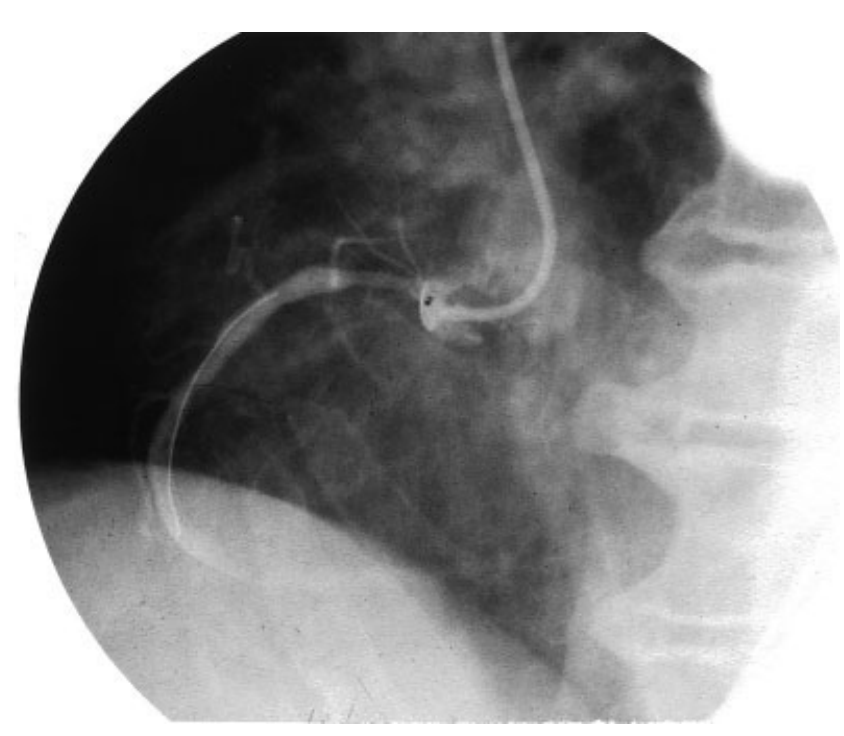

Fig. 2. RCA in LAO view. The guiding catheter is below the origin of the coronary ostium. The BHW guidewire has been advanced to the mid RCA through a lower stent strut.

residual stenosis in the distal lesion with TIMI 3 flow (Figs. 5-6). There were no postprocedure complications and the patient was discharged home the next day. The patient has remained free of any anginal symptoms 19 months postprocedure.

\section{DISCUSSION}

Strategies used for the treatment of aorto-ostial stenosis include directional atherectomy [7-9], laser angio-

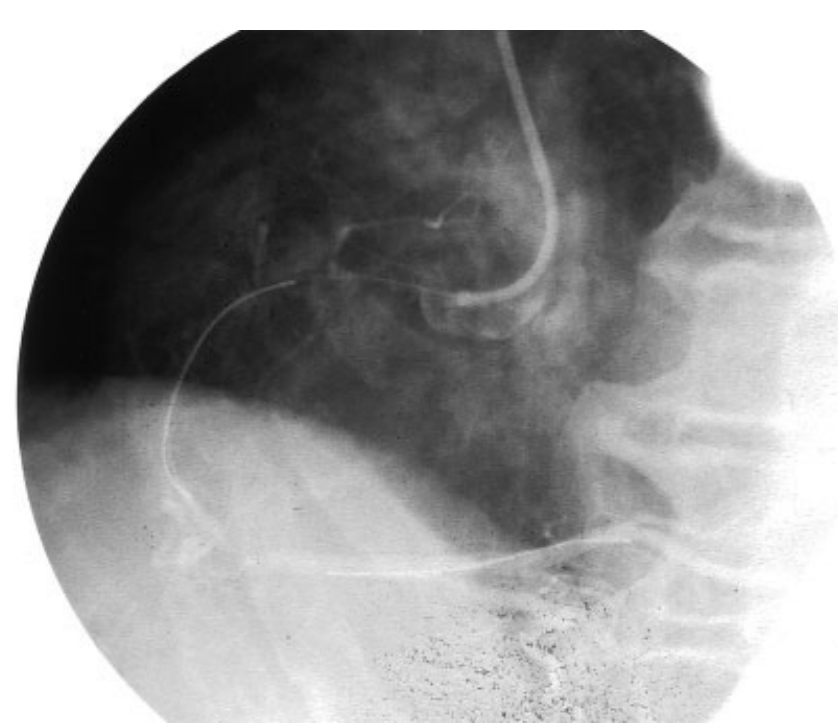

Fig. 3. RCA in LAO view. The guiding catheter is now coaxial with the origin of the RCA, and a second guidewire has been advanced to the distal third of the RCA.

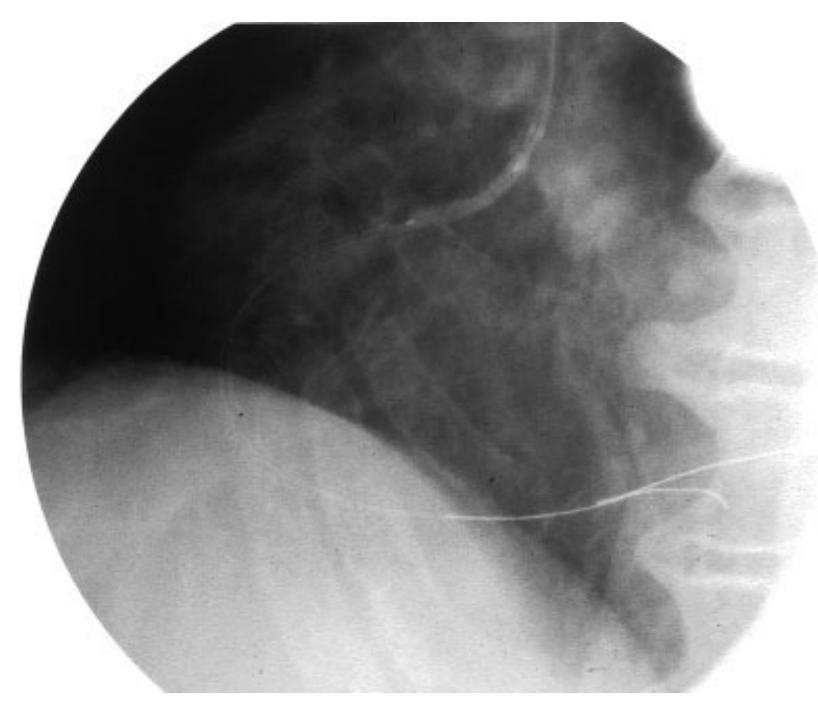

Fig. 4. Inflation of the balloon inside the ostial stent. The distal ends of both guidewires can be visualized in the distal RCA.

plasty [10], rotational atherectomy [11,12], and cutting balloon angioplasty [13]. More recently, coronary stenting alone or in combination with plaque modification techniques has emerged as the dominant procedure for the treatment of aorto-ostial stenosis [14-16]. The endoluminal scaffolding provided by stents results in a reduction in adventitial contraction [17,18] and elastic recoil $[19,20]$, probably accounting for the observed reduction in angiographic restenosis. However, stenting in the aorto-ostial position is technically challenging and fraught with difficulty. Precise placement to ensure adequate covering of the ostium without excessive extrusion 


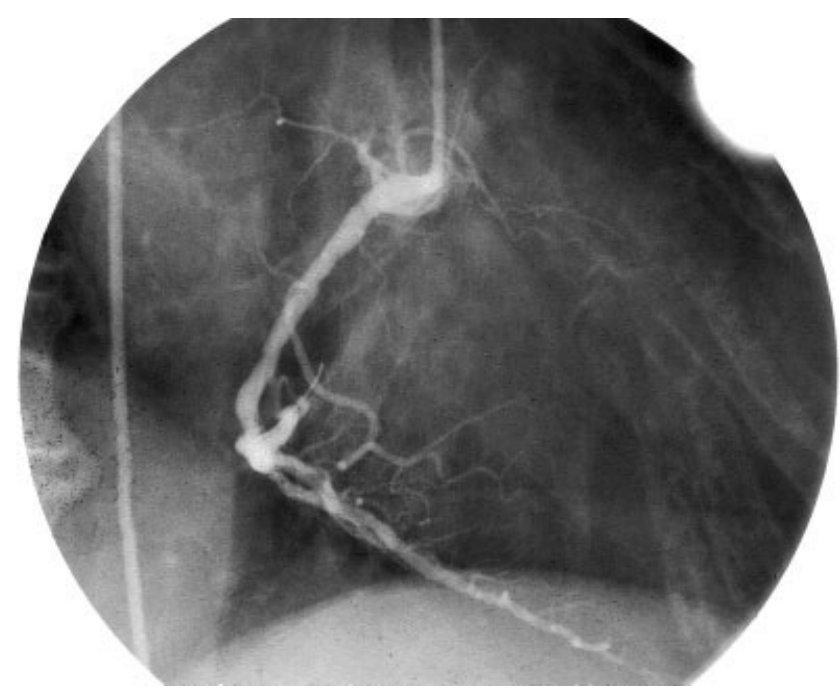

Fig. 5. RCA in RAO view. There is no residual stenosis in the distal stent and $<30 \%$ residual stenosis in the ostial stent.

of the stent into the aorta is paramount. This is made more difficult by the fact that the guiding catheter must be completely removed from the ostium to avoid it being trapped by the stent while keeping it close enough to allow visualization of the aorto-ostial area. Mild anomalies of the origin of coronary arteries will enhance the complexity of stenting of aorto-ostial lesions. These difficulties were clearly recognized in the early stent era and ostial lesions were excluded from the two randomized studies that showed improved restenosis rates of stenting versus balloon angioplasty [21,22].

Our case illustrates two of the complications of aortoostial stenting: in-stent restenosis and protrusion of the stent into the aorta. Stent protrusion cannot be easily seen angiographically and may make coaxial alignment of a cardiac catheter difficult. It may be clearly documented at the end of a procedure with intravascular ultrasound, and it might result in damage of the stent struts and crush of the origin at the time of subsequent cardiac catheterization. Failure to allow for coaxial alignment may also result in advancement of a guidewire through a stent strut. Although treatment of restenosis through stent struts has been reported [23], this may result in device entrapment [24,25] and even in stent extraction [26]. In our case, we made use of the guidewire advanced through a stent strut to support and lift our guiding catheter in a maneuver to align it in a coaxial position and allow the passage of a second guidewire through the true lumen. This maneuver was successful in allowing repeat target lesion revascularization. We did not perform an intravascular ultrasound to confirm advancement of the second guidewire through the true lumen. However, before balloon dilatation, the balloon was advanced multi-

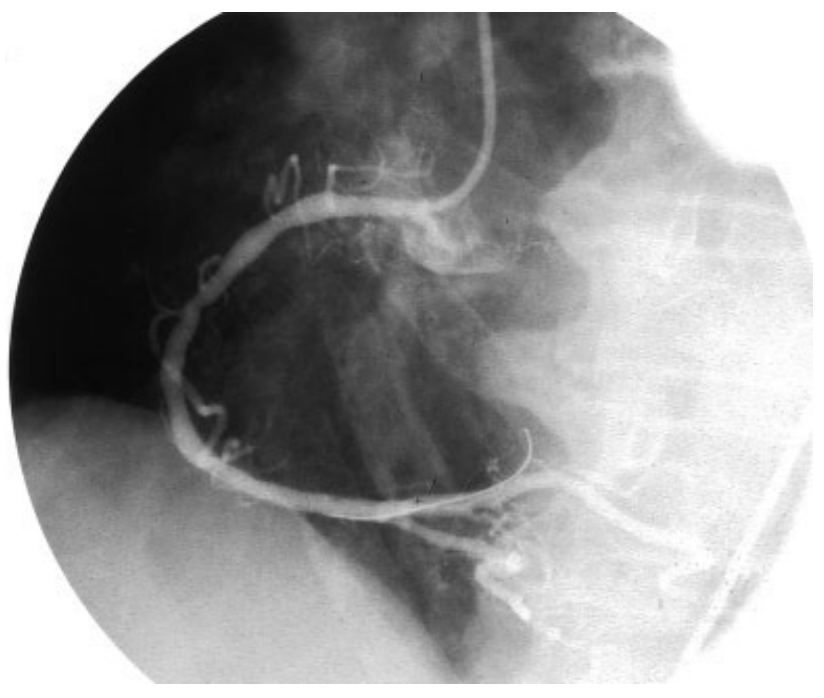

Fig. 6. RCA in LAO view. There is no residual stenosis in the distal stent and $<30 \%$ residual stenosis in the ostial stent.

A

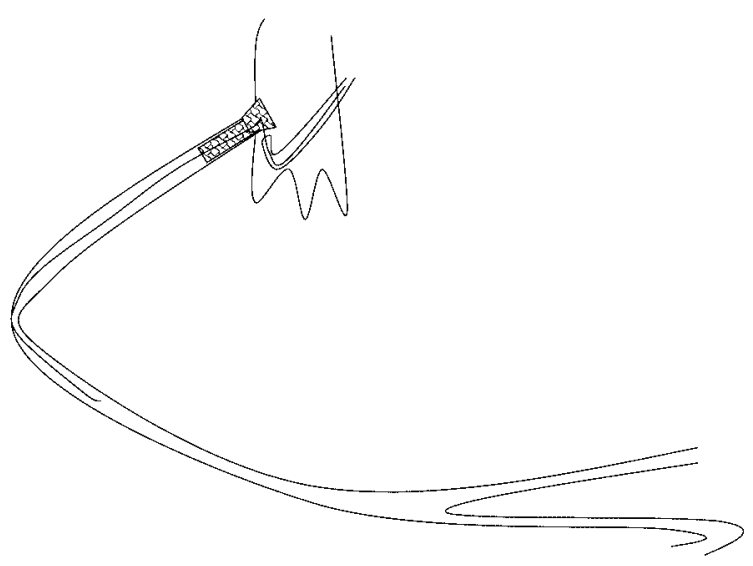

B

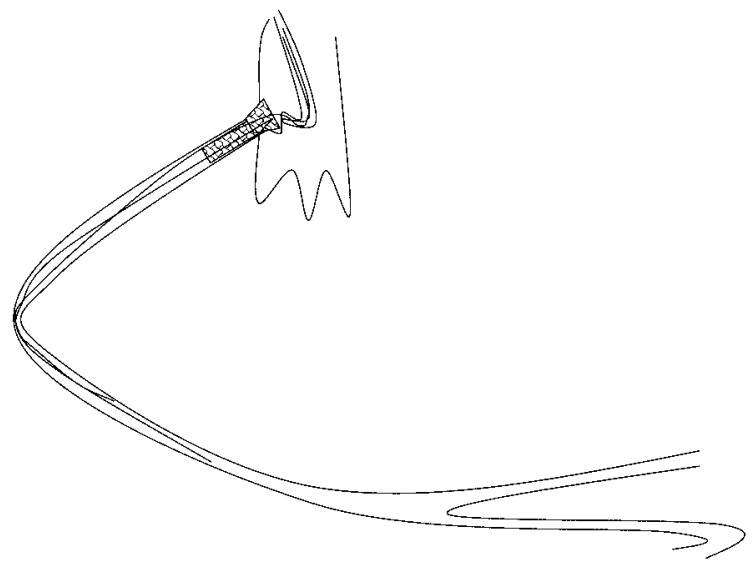

Fig. 7. Schematic representation of the position of the stent and of the relationship between guiding catheter, ostial stent, and the two guidewires. In $\mathrm{A}$, the first guidewire has been advanced through a lower stent strut. In $B$, the guiding catheter has been lifted and a second guidewire has been advanced through the central lumen of the stent. 
ple times through the stent to confirm lack of entrapment. In addition, no resistance was encountered in withdrawing the rewrapped balloon in the guiding catheter, thus supporting our conviction of advancement of the second guidewire through the true lumen of the stent.

In conclusion, our case illustrates a potential limitation of aorto-ostial stenting, and how a double-wire technique might help in overcoming this limitation.

\section{REFERENCES}

1. Topol EJ, Ellis SG, Fishman J, Leimgruber P, Myler RK, Stertzer SH, O'Neill WW, Douglas JS, Roubin GS, King SB III. Multicenter study of percutaneous transluminal angioplasty for right coronary ostial stenosis. J Am Coll Cardiol 1987;9:1214-1218.

2. Holmes DR Jr, Vliestra RE, Smith HC, Vetrovec GW, Kent KM, Cowely MJ, Faxon DP, Gruentzig AR, Kelsey SF, Detre KM, Van Raden MJ, Mock MA. Restenosis after percutaneous transluminalcoronary angioplasty (PTCA): a report from the PTCA registry of the National Heart, Lung and Blood Institute. Am J Cardiol 1984;53:77C-81C

3. Daugoise V, Guiterasval P, David PR, Lesperance J, Crepeau J, Dryde I, Bourassa MG. Recurrence of stenosis after successful percutaneous transluminal coronary angioplasty. Circulation 1982;66(Suppl 2):II331.

4. Rensing BJ, Hermann WR, Strauss BH, Serruys PW. Regional differences in elastic recoil after percutaneous transluminal coronaryangioplasty: a quantitative angiographic study. J Am Coll Cardiol 1991;17:34B-38B.

5. Haude M, Erbel R, Issa H, Meyer J. Quantitative analysis of elastic recoil after balloon angioplasty and after intracoronary implantation of balloon-expandable Palmaz-Schatz stents. J Am Coll Cardiol 1992;21:26-34, 1993.

6. Lederman RJ, Moscucci M. Superimposed stents in the management of acute recoil after Palmaz-Schatz stenting. Cathet Cardiovasc Diagn 1998;44:407-410.

7. Popma J, Dick R, Haudenschild C, Topol E. Atherectomy of right coronary artery ostial stenoses: initial and long-term results, technical features, and histologic findings. Am J Cardiol 1991;67:431433.

8. Stephan WJ, Bates ER, Garratt KN, Hinohara T, Muller DW. Directional atherectomy of coronary and saphenous vein graft ostial stenoses. Am J Cardiol 1995;75:1015-1018.

9. Kerwin PM, McKeever LS, Marek JC, Hartmann JR, Enger EL. Directional atherectomy of aorto-ostial stenoses. Cathet Cardiovasc Diagn 1993;1(Suppl 1):17-25.

10. Eigler NL, Weinstock B, Douglas JS Jr, Goldenberg T, Hartzler G, Holmes D, Leon M, Margolis J, Nobuyoshi M, O’Neill W. Excimer laser coronary angioplasty of aorto-ostial stenoses: results of the excimer laser coronary angioplasty (ELCA) registry in the first 200 patients. Circulation 1993;88:2049-2057.

11. Popma JJ, Brogan WC III, Pichard AD, Satler LF, Kent KM, Mintz GS, Leon MB. Rotational coronary atherectomy for ostial stenosis. Am J Cardiol 1993;71:436-438.

12. Safian RD, Freed M, Reddy V, Kuntz RE, Baim DS, Grines CL, O'Neill WW. Do excimer laser angioplasty and rotational atherec- tomy facilitate balloon angioplasty? implications for lesion-specific coronary intervention. J Am Coll Cardiol 1996;27:552-559.

13. Gambhir DS, Batra R, Singh S, Sudha R, Trehen V, Arora R, Kurbaan AS, Kelly PA, Sigwart U. Cutting balloon angioplasty and stenting for aorto-ostial lesions. Heart 1997;77:350-352.

14. Terstein P, Stratienko AA, Schatz RA. Coronary stenting for ostial stenosis: initial results and six month follow-up. Circulation 1991; 84(Suppl 2):II-250.

15. Zampieri P, Colombo A, Almagor Y, Maiello L, Finci L. Results of coronary stenting of ostial lesions. Am J Cardiol 1994;73:901903.

16. Rocha-Singh K, Morris N, Wong SC, Schatz RA, Teirstein PS. Coronary stenting for treatment of ostial stenoses of native coronary arteries or aorto-cororonary venous grafts. Am J Cardiol $1995 ; 75: 26-29$

17. Hoffmann R, Mintz GS, Dussaillant GR, Popma JJ, Pichard AD, Satler LF, Kent KM, Griffin J, Leon MB. Patterns and mechanisms of in-stent restenosis: a serial intravascular ultrasound study. Circulation 1996;94:1247-1254.

18. Mintz GS, Popma JJ, Pichard AD, Kent KM, Satler LF, Wong C, Hong MK, Kovach JA, Leon MB. Arterial remodeling after coronary angioplasty: a serial intravascular ultrasound study. Circulation 1996;94:35-43.

19. Haude M, Erbel R, Issa H, Meyer J. Quantitative analysis of elastic recoil after balloon angioplasty and after intracoronary implantation of balloon-expandable Palmaz-Schatz stents. J Am Coll Cardiol 1993;21:26-37.

20. Somitsu Y, Ikari Y, Ui K, Nakamura M, Hara K, Saeki F, Degawa $\mathrm{T}$, Tamura T, Yabuki S, Yamaguchi T. Elastic recoil following percutaneous transluminal coronary angioplasty and PalmazSchatz stent implantation. J Invas Cardiol 1995;7:165-172.

21. Serruys PW, de Jaegere P, Kiemeneij F, Macaya C, Rutsch W, Heyndrickx G, Emanuelsson H, Marco J, Legrand V, Materne P, Belardi J, Sigwart U, Colombo A, Goy JJ, van den Heuvel P, Delcan J, Morel MA, for the Benestent study group. A comparison of balloon-expandable-stent implantation with balloon angioplasty in patients with coronary artery disease. N Engl J Med 1994;331: $489-495$.

22. Fischman DL, Leon MB, Baim DS, Schatz RA, Savage MP, Penn I, Detre K, Veltri L, Ricci D, Nobuyoshi M, Cleman M, Heuser R, Almond D, Teirstein PS, Fish RD, Colombo A, Brinker J, Moses J, Shaknovich A, Hirshfeld J, Bailey J, Ellis S, Rake R, Goldberg $\mathrm{S}$, for the Stent Restenosis Study investigators. A randomized comparison of coronary-stent placement and balloon angioplasty in the treatment of coronary artery disease. N Engl J Med 1994; 331:496-501.

23. Abhyankar A, Gai L, Bailey BP. Angioplasty through a stent sidedoor. Int J Cardiol 1996;55:107-110.

24. Caputo RP, Chafizadeh ER, Stoler RC, Lopez JJ, Cohen DJ, Kuntz RE, Carrozza JP Jr, Baim DS. Stent jail: a minimumsecurity prison. Am J Cardiol 1996;77:1226-1229.

25. Chan AW, Lohavanichbutr K, Carere RG, Webb JG. Balloon entrapment during side-branch angioplasty through a stent. Catheter Cardiovasc Interv 1999;46:202-204.

26. Harb TS, Ling FS. Inadvertent stent extraction six months after implantation by an entrapped cutting balloon. Catheter Cardiovasc Interv 2001;53:415-419. 